Dicle University Journal of Engineering (DUJE)

web: http://dergipark.gov.tr/dumf

Araştırma Makalesi / Research Article

\title{
Tetrachloroethylene ve Peroksiasetik Asit ile Klasik ve Mikrodalga Enerji Kullanarak Kömürlerden Organik Desülfürizasvon
}

\section{Sulphur Desulfurization from Coal with Tetrachloroethylene and Peroxyacetic Acid by Conventional and Microwave Heating}

Selçuk Özgen ${ }^{1 *}$, Okyat Bayat ${ }^{2}$

${ }^{1}$ Türkiye Kömür İşletmeleri Genel Müdürlüğü, Ankara, ozgens@ @ki.gov.tr; ozgen_s@ @hotmail.com

${ }^{2}$ Çukurova Üniversitesi, Maden Mühendisliği Bölümü, Adana, obayat@cu.edu.tr

\begin{tabular}{l} 
MAKALE BİLGİLERİ \\
\hline Makale geçmişi: \\
Geliş: 6 Nisan 2020 \\
Düzeltme: 2 Temuuz 2020 \\
Kabul: 3 Temmuz 2020 \\
\hline Anahtar kelimeler: \\
Desülfirizasyon, organik sülfür, \\
kömür, mikrodalga, kimyasal liç
\end{tabular}

Doi: $10.24012 /$ dumf. 715417

\begin{abstract}
ÖZET
Kömürdeki en önemli sülfür formları piridik kükürt olarak adlandırılan sülfitler ve kömüre moleküler olarak bağlı olan organik sülfürlerdir. Piridik kükürt yeterli serbeştleşme sağlanarak kömürden uzaklaştırılabilmesine rağmen organik sülfür moleküler olarak bağlı olduğu için kömürle birlikte hareket eder. Bu çalışmada tetrachloroethylene $\left(\mathrm{C}_{2} \mathrm{Cl}_{4}\right)$ ve peroksiasetik asit $\left(\mathrm{C}_{2} \mathrm{H}_{4} \mathrm{O}_{3}\right)$ ile $\mathrm{C}$-S bağları kırılarak organik sülfürün uzaklaştırılması araştırılmıştır. Ayrıca, hangi 1sıtma tekniğinin daha avantajlı olduğunu belirlemek için organik kükürt uzaklaştırma deneylerinde klasik ve mikrodalga 1sıtma kullanılmıştır. Çalışmalar kapsamında toplam kükürt içeriği $\% 4,77$ olan Çanakkale/Çan kömürleri kullanılmış ve \%75,94 kükürt uzaklaştırma oranı (KUO) ile toplam kükürt içeriği $\% 1,15$ 'e düşürülmüştür. Nihai üründeki organik kükürt uzaklaştırma oranı (OKUO) ise \%86,10 olarak hesaplanmış ve bu ürünün \%0,51 organik kükürt içerdiği belirlenmiştir. Ayrıca, mikrodalga 1sıtmanın klasik 1sıtma yöntemine göre çok kısa sürede daha fazla kükürt uzaklaştırdığı belirlenmiştir.
\end{abstract}

* Sorumlu yazar / Correspondence

Selçuk ÖZGEN

$\square$ ozgens@tki.gov.tr; ozgen_s@hotmail.com 


\section{Giriș}

Sanayileşmenin hızla artması enerji talebindeki artışı da beraberinde getirmektedir. Artan talebi karş1lamak için enerji tasarrufunu gerekli önemi vermek ve yenilenebilir enerji kaynağ 1 olan linyitlerimizin kullanımını artırmak gerekmektedir. Ancak, yerli linyitlerimizin düşük 1sıl değerli (\%65'i 2000 kcal/ $/ \mathrm{kg}^{\prime} ı$ altında) ve yüksek kükürt içerikli (\%1-5 S) olması, hava/çevre kirliliği ve dolayısıyla insan sağlığı açısından düşünüldüğünde termik santrallerde kullanımı zorlaşmaktadır [1-2]. Linyitlerin kalorifik değeri basit ve düşük maliyetli metotlar kullanılarak artırılabilmesine rağmen içerdiği kükürt çeşitli sorunlara neden olmaktadır. $\mathrm{Bu}$ yüzden bazı durumlarda uzaklaştırılması bir zorunluluk haline gelmektedir.

Kömürde bulunan kükürt formları sülfitler, sülfatlar, organik sülfür ve elementel sülfür olarak dört gruba ayrılmasına rağmen en önemli kükürt formu sülfitler olarak adlandırılan pirit ve markasit gibi mineraller ile kömüre moleküler olarak bağlanmış organik sülfürlerdir [3]. Sülfitler olarak adlandırılan piridik sülfürler makul derecede serbestleşme sağlanarak gravite, manyetik veya fiziko-kimyasal ve kimyasal yöntemlerle kömürden uzaklaștırılabilir [4-6]. Organik kükürt ise moleküler olarak bağlı olduğu için fiziksel yada fiziko-kimyasal yöntemlerle uzaklaştırılması imkansıza yakındır. Bu kükürt türünü uzaklaştırabilecek en etkin yöntemler kimyasal yöntemlerdir. Kimyasal yöntemlerde kullanılan kimyasal maddeleri ise asitler, bazlar, çözücüler, indirgeyici veya yükseltgeyiciler olabilmektedir [7-10].

Palmer vd. [11], oksidasyon yöntemiyle kömürden organik sülfürü uzaklaştırmaya çalışmışlardır. Bunun için kömür ile bir oksitleyici olan hidrojen peroksit $\left(\mathrm{H}_{2} \mathrm{O}_{2}\right)$, perasedik asit $\left(\mathrm{C}_{2} \mathrm{H}_{4} \mathrm{O}_{3}\right)$, potasyum permanganat $\left(\mathrm{KMnO}_{4}\right)$ ve sodyum dikromat1 $\left(\mathrm{Na}_{2} \mathrm{Cr}_{2} \mathrm{O}_{7}\right)$ kullanarak muamele etmişler ve daha sonra methanol $\left(\mathrm{CH}_{4} \mathrm{O}\right)$ türü çözücüde organik kükürdü uzaklaştırmışlardır. Bu sayede organik ve inorganik sülfürün bir kısmını uzaklaştırmışlardır. Zhao vd. [12], asetik asit $\left(\mathrm{C}_{2} \mathrm{H}_{4} \mathrm{O}_{2}\right)$ ve hidrojen peroksit $\left(\mathrm{H}_{2} \mathrm{O}_{2}\right)$ karışımlarını kullanarak kömürden organik kükürdü oksitleyerek uzaklaştırmaya çalışmışlardır. En iyi sonucu $-0,23 \mathrm{~mm}$ tane boyutunda, $104{ }^{\circ} \mathrm{C}$ reaksiyon sicaklığında 1 saat liç yaparak elde etmişlerdir. Bu şartlarda organik kükürdün \%60,8'ini uzaklaştırmışlardır.

Jorjani vd. [13], \%1,44 toplam kükürt içeren İran Tabas kömürlerinden piritik ve organik kükürdün uzaklaştırılmasında mikrodalga enerji ve peroksiasetik asiti (PAA) kullanmışlardır. Mikrodalga enerji süresi ve kimyasal konsantrasyonunun artışı ile bünyeden uzaklaştırılan kükürt miktarında arttığını belirlemişlerdir. Yapılan çalışmalar neticesinde piritik kükürdün büyük çoğunluğunun, toplam kükürdün ise \%61,89'unun uzaklaştırılabildiğini belirlemişlerdir. Aynı araştırmacılar yaptıkları bir başka çalışmada aynı kömürleri kullanarak farklı oksidasyon yöntemleri (açık havada ve PAA ile oksidasyon) ve sodyum batoksitin etkileri araştırmışlardır. Bu çalıșmalarında ise piritik kükürtte $\% 84$, organik kükürtte $\% 49$ ve toplam kükürtte $\% 67$ oranında uzaklaştırma sağladıklarını ifade etmişlerdir [14]. Benzer olarak Sönmez ve Giray [15]'da yüksek oranda kükürt içeren Çayırhan $(\% 5,2)$ ve Gediz yöresi $(\% 7,6)$ kömürlerinden kükürdün uzaklaştırılması amaciyla peroksiasetik asit (PAA) kullanılmışlardır. Seçimli olarak kükürdü oksitleyebilen peroksiasetik asidin kullanılması ile yapılan bu çalışma ile Çayırhan linyitlerinden $\% 80$, Gediz yöresi linyitlerinden ise $\% 40$ oranında toplam kükürt uzaklaştırılabilmiştir. Jorjani ve arkadaşları [13] yaptığı başka bir çalışmada ise perasetik asit ile mikrodalgada kömürden sülfür uzaklaştırmaya çalışmışlar ve $0,3 \mathrm{~mm}$ tane boyutunda inorganik kükürdün maksimum \%86,6'sını organik kükürdün \%35'ini uzaklaştırmışlardır. Ahmed ve Rahim [16], ethanol $\left(\mathrm{C}_{2} \mathrm{H}_{6} \mathrm{O}\right)$, dimetilbenzen $\left(\mathrm{C}_{8} \mathrm{H}_{10}\right)$, benzen $\left(\mathrm{C}_{6} \mathrm{H}_{6}\right)$ ve piridin $\left(\mathrm{C}_{5} \mathrm{H}_{5} \mathrm{~N}\right)$ gibi organik çözücüler ile $\mathrm{Na}_{2} \mathrm{CO}_{3}, \mathrm{KOH}$, Methanol $\left(\mathrm{CH}_{4} \mathrm{O}\right), \mathrm{NaOH}$, $\mathrm{Na}_{2} \mathrm{SO}_{3}$ gibi inorganik çözücüleri organik kükürdün uzaklaştırılmasında kullanmışlardır. En iyi organik çözücüyü Etil alkol ve dimetilbenzenin 1:1 oranlarında karışımıyla elde etmişler ve kömürdeki organik kükürdün \%67,20'sini uzaklaştırmışlardır. En iyi inorganik çözücü olarak ta $\mathrm{NaOH}$ 'li belirlemişler ve organik kükürdün \%67,20'sini uzaklaştırmışlardır. Zhao vd. [17], 
tetrachloroethylene $\left(\mathrm{C}_{2} \mathrm{Cl}_{4}\right)$ ile $0,074 \mathrm{~mm}$ boyutundaki sülfürlü kömürleri liç işlemine tabi tutmuşlar ve organik sülfürün $\% 50,2$ 'sini uzaklaştırmışlardır. Longjun vd. [18], 1-phrpyl alcohol $\left(\mathrm{C}_{3} \mathrm{H}_{8} \mathrm{O}\right)$ kullanarak kömürdeki organik kükürdün \%42,29-60,70'ini uzaklaştırmışlardır. $\mathrm{Mi}$ vd. [19] tetrachloroethylene $\left(\mathrm{C}_{2} \mathrm{Cl}_{4}\right)$ kullanarak kömürlerden kükürt uzaklaştırılmasını mikrodalga enerji ve ultrasonik dalga vererek araştırmışlardır. -0,1 mm tane boyutundaki kömürü 70 dakika ultrasonik dalga vererek ve 30 dakika $280 \mathrm{~W}$ mikrodalgada 1sıtarak \%51,6 sülfür uzaklaştırma sağlamışlardır. Mi ve Wei [20] yine ultrasonik ve mikrodalga enerjisi altında tetrachloroethylene kullanarak sülfür uzaklaştırmaya çalışmışlardır. Çalışmalarından önce kullanacakları kömürü HNO3 ile muamele ederek inorganik kükürdün tamamını uzaklaştırmışlardır. İnorganik kükürdü uzaklaştırarak kullandıkları \%0,94 organik sülfür içerikli kömürün 30 dakika boyunca yapılan liç işlem sonucunda $\% 45$ organik sülfür uzaklaşmıştır.

Ultrasonik ses dalgaları ve mikrodalga 1sıtmanın kullanıldığı bir başka çalışmada Jie vd. [21] Çin kömür numunelerindeki kömürü oluşturan maseral grupları ayrı ayrı belirlemiş ve her bir maseralin içerdiği kükürt türleri (organik, piritik, sülfat) belirlenmeye çalıșılmıștır. Daha sonra peroksiasetik asit (PAA) ile ultrasonik ses dalgaları ve mikrodalga enerji yardımı ile kükürt uzaklaştırma çalışmaları gerçekleştirilmiştir. Yapılan çalışma ile maseral grupları ve içerdikleri kükürdün uzaklaştırılma olanakları incelenmiş ve en kolay mineral madde inertinitten, en zor vitrinitten kükürt uzaklaştırılabildiği belirlemişlerdir. Bu çalışma ile $\% 53,1$ oranında kükürdün bünyeden uzaklaştırılabildiğini saptamışlardır.
Her ne kadar farklı araştırmacılar farklı kimyasal türleri ile bazı çalışmalar yapmış olsada ya yeterli kükürt uzaklaştırma sağlanamamış yada kullanılan yöntem ekonomik olmamıştır. Bu yüzden bu çalışmada klasik ısıtma ve mikrodalga 1sıtmanın etkisi karşılıklı olarak araştırılmış ve avantajlı olan 1sitma tekniği ve kullanilan parametrelerin organik kükürt uzaklaştırmaya etkisi belirlenmiştir. Çalışmalarda Çanakkale/Çan kömürlerindeki organik kükürdün uzaklaştırılması için daha önceki çalışmalarda etkili olabilecekleri belirtilen tetrachloroethylene $\left(\mathrm{C}_{2} \mathrm{Cl}_{4}\right)$ ve peroksiasetik asit $\left(\mathrm{C}_{2} \mathrm{H}_{4} \mathrm{O}_{3}\right)$ kullanılmıştır. Her iki kimyasal da her iki 1sıtma tekniğinde kullanılarak optimum şartlar belirlenmiştir.

\section{Materyal ve Metot}

\section{Materyal}

Çalışmada kullanılan kömür numuneleri yüksek kükürt içeriğine sahip olduğu bilinen Çanakkale/Çan kömür sahalarından alınmıştır. Havada kuru olarak yapılan tam kömür analizleri Çizelge 1'de verilmiştir. Kömürlerin Kül ve uçucu madde analizlerinde ASTM D 3174, kükürt analizlerinde ASTM D 4239, Nem analizlerinde TSE 690, farklı bazlarda analizlerin hesaplanmasinda ise ISO 1170 ve ISO 1988 kullanılmıştır. Ayrıca organik kükürt hesaplamaları TS 329 ISO 157 standardına uygun olarak gerçekleştirilmiş olup toplam kükürt değerinden sülfat ve piritik kükürdün çıkarılması ile bulunmuştur. Analiz sonuçlarına göre deneylerde toplam kükürt içeriği $\% 4,77$ olan kömür numuneleri kullanılmış olup, bu numunelerin organik kükürt içeriği \%3,67 olarak hesaplanmıştır.

\section{Çizelge 1. Numunelere ait kömür analizi}

\begin{tabular}{|c|c|c|c|c|c|c|c|c|}
\hline \multicolumn{3}{|c|}{ Kömür Analizi } & \multicolumn{3}{|c|}{ Elementel Analiz } & \multicolumn{3}{|c|}{ Kükürt Dağılımı } \\
\hline Toplam Nem & $\%$ & 2,28 & Karbon & $\%$ & 24,29 & Organic Sulphur & $\%$ & 3,67 \\
\hline Kül & $\%$ & 54,98 & Hidrojen & $\%$ & 2,43 & Pyrite Sulphur & $\%$ & 0,41 \\
\hline Uçucu Madde & $\%$ & 28,59 & Azot & $\%$ & 0,31 & Sulphate Sulphur & $\%$ & 0,69 \\
\hline Sabit Karbon & $\%$ & 14,16 & Oksijen & $\%$ & 10,33 & & & \\
\hline Alt Isıl Değer & $\mathrm{Kcal} / \mathrm{kg}$ & 2.101 & Toplam Kükürt & $\%$ & 4,77 & & & \\
\hline
\end{tabular}


Metot

\section{Kömür Hazırlama}

-100 mm tane boyutuna sahip olan kömür örnekleri önce çeneli kırıcı ile $1 \mathrm{~cm}$ altına kırılmış daha sonra çekiçli değirmen ile $0,5 \mathrm{~mm}$ tane boyutunun altına ögütülmüştür. Öğüttülen kömür numuneleri standartlara uygun olarak bölünerek kurutulmuş ve kimyasal liç için hazır hale getirilmiştir.

\section{Organik kükürt uzaklaştırma}

Toplam kükürt içeriği $\% 4,77$, organik kükürt içeriği \%3,67 olan kömür numunesinden tetrachloroethylene $(\mathrm{C} 2 \mathrm{Cl} 4)$ ve peroksiasetik asit (C2H4O3) kullanılarak organik kükürt uzaklaştırılmaya çalışılmıştır.

Tetrachloroethylene (C2Cl4): TCE olarak isimlendirilen tetrachloroethylene, mükemmel bir organik madde çözücüdür. Uçuculuğu ve yanıcı olmayışı nedeniyle kuru temizlemede kullanılmaktadır. Kömürden özellikle organik kükürt uzaklaştırılmasında kullanılmış ve bu yolla organik kükürdün \%50'ye yakını uzaklaştırılmış, ayrıca bir miktarda kül uzaklaştırdığı bazı araştımacılar tarafından rapor edilmiştir.

Peroksiasetik asit (C2H4O3): Kisaca PAA olarak isimlendirilen peroksiasetik asit, asetik asit (C2H4O2) ile hidrojen peroksidin (H2O2) belirli oranlarda karıştırılması ile elde edilen bir asit türüdür. Peroksiasetik asit, kömür bünyesindeki kükürt türlerinin oksitlenmesini sağlayıp çözülebilen yapılara dönüştürerek kömürden kükürt ve çeşitli kül yapıcı maddelerin uzaklaştırılması amacıyla kullanılan bir kimyasaldır. Peroksiasetik asidin organik kükürt türlerini sellektif olarak oksitlemesi, bünyeden organik kükürdün uzaklaştırılmasında etkili olmakta, ancak uzaklaştırılan organik kükürt miktarı sınırlı seviyelerde kalmaktadır.

Kükürt uzaklaştırma deneyleri Çizelge 2'deki deney pararmetreleri kullanılarak hem klasik 1sitma hem de mikrodalga isitma teknikleri kullanılarak 250 cc beherlerde yapılmıştır. Klasik 1sıtma yönteminde çözeltiyi 1sıtmak için Wisd Wisestir marka MSH-20D model 1siticilı manyetik karıştırıcı kullanılırken mikrodalga 1sitma tekniğinde Lab-Kits brand MW-ER-02 model ultrasonik/mikrodalga reaktör kullanılmıştır. Burada mikrodalga gücü ısıtma amacıyla kullanılmış, karıştırma amacıyla ultrasonik dalga uygulanmıştır. Her iki ısıtma tekniğinde de deney sonrası katı numune filtre edilerek ayrılmış, $3 \mathrm{kez}$ saf su ile yıkandıktan sonra $100{ }^{\circ} \mathrm{C}$ 'de 2 saat kurutulmuştur. Elde edilen kömür örneklerine toplam kükürt analizleri yapılarak toplam kükürt uzaklaştırma oranı (KUO) Denklem 1 ile hesaplanmıştır. Her deney için organik kükürt analizi yapılmamış olup en yüksek KUO elde edilen örneklerde organik kükürt analizleri yapılmıştır.

Kükürt Uzak. Oranı $(\%)=\frac{K_{F}-K_{C}}{K_{F}} x 100$

Burada; $K_{F}$ : Beslemenin toplam kükürt içeriği (\%), $K_{C}$ : deney sonrası toplam kükürt içeriği (\%)

Çizelge 2. Klasik ve Mikrodalga isitma test parametreleri.

\begin{tabular}{|l|l|c|l|l|}
\hline \multirow{2}{*}{ Deney Türü } & Bağımsız Değişken & Sembol & Alt Sınır & Üst Sınır \\
\hline \multirow{4}{*}{ Klasik Isıtma } & Kimyasal konsantrasyon (M) & KK & 0.1 & 0.3 \\
\cline { 2 - 5 } & Reaksiyon sıcaklı̈̆ı $\left({ }^{\circ} \mathrm{C}\right)$ & $\mathrm{S}$ & 30 & 90 \\
\cline { 2 - 5 } & Reaksiyon süresi (dk) & $\mathrm{Z}$ & 30 & 120 \\
\cline { 2 - 5 } & Karışırıma hızı (rpm) & KH & 600 & 1350 \\
\cline { 2 - 5 } & Katı oranı (\%) & KO & 5 & 20 \\
\hline \multirow{4}{*}{ Mikrodalga Isıtma } & Kimyasal konsantrasyon (M) & KK & 0.1 & 0.3 \\
\cline { 2 - 5 } & Reaksiyon süresi (dk) & Z & 5 & 20 \\
\cline { 2 - 5 } & Mikrodalga gücü (W) & MG & 400 & 1200 \\
\cline { 2 - 5 } & Katı oranı (\%) & KO & 5 & 20 \\
\hline
\end{tabular}




\section{Istatistiksel Analiz}

İstatistiksel yöntemler, gözlemlerden bilgi edinmek ve temsil eden sayılardan doğru anlamlar çıkarmak amacıyla, bir araya getirilen verilerin analizinde kullanılır. İstatistiksel deney tasarımının amacı minimum zaman, kaynak ve harcama ile maksimum anlamlı verileri elde etmektir. Bundan dolayı deney tasarımı geleneksel yöntemlerden uzak ve araştırmalara yeni bir yaklaşım getirmektedir. Geleneksel deney tasarım yöntemlerinde yüksek malzeme maliyeti, uzun zaman alması ve en önemlisi fazla sayıda analiz ile yüksek maliyetler oluşturmaktadır. Geleneksel yöntemlerde her bir parametrenin deney üzerindeki etkisini araştırmak için diğer bütün parametreler sabit tutulmakta ve her seferinde farklı bir parametre denenmektedir. Bu şekilde hem deney sayıs1 artmakta hem de parametreler arası iç etkileşim gözardı edilmektedir. Bu yüzden geleneksel yöntemlerle yapılacak çalışmalarda parametreler ve seviyeleri sinırlı sayıda tutulmakta ve sonuca ulaşmak zorlaşmaktadır.

Günümüzde hemen hemen her bilim dalında kullanılan istatistiksel deney tasarım yöntemleri, bu çalışma kapsamında yapılacak olan linyit kömürlerinden organik kükürdün uzaklaştırılmasında da kullanılmıştır. Deney tasarımı, merkezi kompozit tasarımı olan BoxBehnken deney tasarım yöntemi ile yapılmıştır. Deneyler sonucu elde edilen verilerle kükürt uzaklaştırmayı tanımlayan modeller üretilmiştir. Bu modeller yanıt yüzeyi yöntemleri kullanılarak analiz edilmiş ve optimizasyonu yanıt yüzeyi ile yapılmıştır. Deney tasarımı, yanıtların analizi, modelleme ve grafiklerin çizimi Minitab ${ }^{\circledR} 16$ bilgisayar programı ile yapılmıştır. Çizelge 2'de verilen bağımsız değişken ve seviyeleri kullanılarak klasik 1sıtma metodu için 46 deney-

Çizelge 3. Klasik ısıtma için deneysel kodlama.

\begin{tabular}{|c|c|c|c|c|c|c|c|c|c|c|c|}
\hline \multirow[t]{2}{*}{ Deney No } & \multicolumn{5}{|c|}{ Bağımsız Değişken } & \multirow[t]{2}{*}{ Exp. No } & \multicolumn{5}{|c|}{ Bağımsız Değişken } \\
\hline & KK & $\mathbf{S}$ & $Z$ & KH & KO & & KK & $\mathbf{S}$ & $\mathbf{Z}$ & KH & KO \\
\hline 1 & 0 & 0 & 0 & 0 & 0 & 24 & 0 & 0 & 0 & 0 & 0 \\
\hline 2 & 0 & 1 & 0 & 1 & 0 & 25 & 0 & 0 & 0 & 0 & 0 \\
\hline 3 & 0 & -1 & 0 & 0 & 1 & 26 & 1 & 0 & 0 & -1 & 0 \\
\hline 4 & 0 & -1 & 0 & 0 & -1 & 27 & 0 & 0 & 0 & 0 & 0 \\
\hline 5 & 1 & 0 & 1 & 0 & 0 & 28 & -1 & 0 & 0 & -1 & 0 \\
\hline 6 & 0 & 1 & 1 & 0 & 0 & 29 & 0 & 0 & 0 & 0 & 0 \\
\hline 7 & 0 & -1 & 0 & -1 & 0 & 30 & 1 & 0 & 0 & 0 & -1 \\
\hline 8 & 0 & 0 & 0 & -1 & 1 & 31 & 0 & 0 & 1 & 0 & -1 \\
\hline 9 & 0 & 0 & 1 & 1 & 0 & 32 & -1 & 0 & 0 & 1 & 0 \\
\hline 10 & 0 & -1 & 1 & 0 & 0 & 33 & 0 & 0 & 1 & -1 & 0 \\
\hline 11 & -1 & 1 & 0 & 0 & 0 & 34 & -1 & 0 & 1 & 0 & 0 \\
\hline 12 & 0 & 1 & 0 & -1 & 0 & 35 & 0 & 0 & -1 & -1 & 0 \\
\hline 13 & 1 & 0 & -1 & 0 & 0 & 36 & 0 & 0 & 0 & 1 & -1 \\
\hline 14 & 0 & 0 & 0 & 1 & 1 & 37 & 0 & 0 & 0 & -1 & -1 \\
\hline 15 & 0 & 0 & 1 & 0 & 1 & 38 & -1 & -1 & 0 & 0 & 0 \\
\hline 16 & 1 & 1 & 0 & 0 & 0 & 39 & 0 & -1 & -1 & 0 & 0 \\
\hline 17 & 0 & 0 & -1 & 1 & 0 & 40 & -1 & 0 & 0 & 0 & 1 \\
\hline 18 & 0 & 0 & -1 & 0 & -1 & 41 & 0 & 1 & -1 & 0 & 0 \\
\hline 19 & 0 & 1 & 0 & 0 & 1 & 42 & 1 & 0 & 0 & 1 & 0 \\
\hline 20 & 0 & -1 & 0 & 1 & 0 & 43 & -1 & 0 & 0 & 0 & -1 \\
\hline 21 & 0 & 0 & -1 & 0 & 1 & 44 & 0 & 0 & 0 & 0 & 0 \\
\hline 22 & 0 & 1 & 0 & 0 & -1 & 45 & 1 & -1 & 0 & 0 & 0 \\
\hline 23 & 1 & 0 & 0 & 0 & 1 & 46 & -1 & 0 & -1 & 0 & 0 \\
\hline
\end{tabular}


Çizelge 4. Mikrodalga ısitma için deneysel kodlama.

\begin{tabular}{|c|c|c|c|c|c|c|c|c|c|}
\hline \multirow{2}{*}{ Deney No } & \multicolumn{3}{|c|}{ Bağımsız Değişken } & \multirow{2}{*}{ Deney No } & \multicolumn{4}{|c|}{ Bağımsız Değišken } \\
\cline { 2 - 7 } & KK & $\mathbf{Z}$ & MG & KO & & KK & $\mathbf{Z}$ & MG & KO \\
\hline $\mathbf{1}$ & 0 & 1 & -1 & 0 & $\mathbf{1 5}$ & -1 & 0 & -1 & 0 \\
\hline $\mathbf{2}$ & -1 & 0 & 0 & 1 & $\mathbf{1 6}$ & -1 & 1 & 0 & 0 \\
\hline $\mathbf{3}$ & -1 & 0 & 1 & 0 & $\mathbf{1 7}$ & -1 & -1 & 0 & 0 \\
\hline $\mathbf{4}$ & 1 & 1 & 0 & 0 & $\mathbf{1 8}$ & 0 & 0 & 1 & 1 \\
\hline $\mathbf{5}$ & 0 & 0 & 0 & 0 & $\mathbf{1 9}$ & 1 & 0 & -1 & 0 \\
\hline $\mathbf{6}$ & 1 & -1 & 0 & 0 & $\mathbf{2 0}$ & -1 & 0 & 0 & -1 \\
\hline $\mathbf{7}$ & 0 & 0 & 1 & -1 & $\mathbf{2 1}$ & 0 & 1 & 1 & 0 \\
\hline $\mathbf{8}$ & 0 & -1 & -1 & 0 & $\mathbf{2 2}$ & 1 & 0 & 1 & 0 \\
\hline $\mathbf{9}$ & 1 & 0 & 0 & 1 & $\mathbf{2 3}$ & 0 & -1 & 0 & -1 \\
\hline $\mathbf{1 0}$ & 0 & 0 & 0 & 0 & $\mathbf{2 4}$ & 0 & 1 & 0 & 1 \\
\hline $\mathbf{1 1}$ & 0 & -1 & 1 & 0 & $\mathbf{2 5}$ & 0 & 0 & -1 & 1 \\
\hline $\mathbf{1 2}$ & 0 & 0 & 0 & 0 & $\mathbf{2 6}$ & 0 & 1 & 0 & -1 \\
\hline $\mathbf{1 3}$ & 0 & 0 & -1 & -1 & $\mathbf{2 7}$ & 0 & -1 & 0 & 1 \\
\hline $\mathbf{1 4}$ & 1 & 0 & 0 & -1 & & & & & \\
\hline
\end{tabular}

-(6 merkez nokta), mikrodalga 1sitma için 27 deney ( 3 merkez nokta) belirlenmiş ve hazırlanan deney seti Çizelge 3 ve 4'de verilmiştir. Çizelge -1 bağımsız değişkenin minimum seviyesini, 1 maksimum seviyesini ve 0 ise orta seviyesini göstermektedir. Deneyler sonrasında elde edilen veriler ile Minitab ${ }^{\circledR} 16$ yardımıyla kükürt uzaklaştırma oranını belirleyen 2. dereceden denklemler ve koralasyon katsayıları (R2) hesaplanmıştır.

\section{Sonuçlar ve Tartışma}

Klasik ısıtma yöntemiyle organik kükürt uzaklaştırma

Klasik 1sitma yöntemi ile tetrachloroethylene (TCE) ve peroksiasetik asit (PAA) kullanılarak yapılan 46 deney serisine ait sonuçlar Çizelge 5 'de verilmiştir. Bu sonuçlara göre PAA ile en iyi sonuç Deney $45^{\prime}$ de (Kimyasal kons. $=\% 20$; Sicaklık $=20 \quad{ }^{\circ} \mathrm{C}$; Süre $=75 \quad \mathrm{dk} ; \quad$ Karıştırma $\mathrm{h}_{1 \mathrm{zl}}=975 \mathrm{~d} / \mathrm{d}$; Katı oranı $\left.=\% 12,5\right) \% 56,01 \mathrm{KUO}$ olarak elde edilirken, TCE ile en iyi sonuç Deney 16 'da (Kimyasal kons. $=\% 40$; Sicakl $1 \mathrm{k}=90{ }^{\circ} \mathrm{C}$; Süre $=75 \mathrm{dk}$; Karıştırma hızı $=975 \mathrm{~d} / \mathrm{d}$; Katı oran $1=\% 12,5) \quad \% 71,08 \quad$ KUO olarak elde edilmiștir. Ayrıca Çizelge 5'deki sonuçlar kullanılarak hazırlanan regrasyon modelleri ve katsayıları Çizelge 6' da verilmiştir.

Deneyler sonrasında en iyi sonucun elde edilen deneylerdeki kömür örneklerinin organik kükürt uzaklaştırma oranlarını belirlemek için organik kükürt analizi yapılmıştır. PAA için 45 nolu deneyden elde edilen kömür örneği ve TCE için 16 nolu deneyden elde edilen kömür örneğine ait organik kükürt analiz sonuçları Çizelge 7'de verilmiştir. Çizelgeden de görüldüğü gibi PAA kimyasalı kullanıldığında \%56,01 toplam kükürt uzaklaştırma oranı (KUO) elde edilirken \%67,90 organik kükürt uzaklaştırma oranı (OKUO) elde edilmiştir. TCE kimyasalında ise \%71,08 KUO elde edilirken \%83,55 OKUO elde edilmiştir. OKUO'larının KUO'ndan daha yüksek çıkması bu kimyasalların organik kükürde daha çok etki ettiğini göstermektedir.

\section{Mikrodalga Isıtma Yöntemiyle Organik Kükürt Uzaklaştırma}

Mikrodalga 1sitma yöntemi ile tetrachloroethylene (TCE) ve peroksiasetik asit (PAA) kullanılarak yapılan 27 deney serisine ait sonuçlar Çizelge 8'de verilmiştir. Bu sonuçlara göre PAA ile en iyi sonuç Deney 13'de (Kimyasal kons. $=\% 12,5$; Süre $=12,5 \quad d k$; Mikrodalga gücü $=400$ W; Katı oranı=\%5) \%62,97 KUO olarak elde edilirken, TCE ile en iyi sonuç Deney 22 'de (Kimyasal kons. $=\% 40$; Süre $=12,5$ dk; Mikrodalga gücü=1200 W; Katı oranı=\%12,5) $\% 75,94$ KUO olarak elde edilmiştir. Ayrıca Çizelge 8'deki sonuçlar kullanılarak hazırlanan regrasyon modelleri ve katsayıları Çizelge 9'da verilmiştir. 
Çizelge 5. Klasik ısıtma yöntemi test sonuçları.

\begin{tabular}{|c|c|c|c|c|c|c|c|c|}
\hline \multirow{2}{*}{$\begin{array}{c}\text { Sira } \\
\text { No }\end{array}$} & \multicolumn{2}{|c|}{ KUO } & \multirow{2}{*}{$\begin{array}{c}\text { Sira } \\
\text { No }\end{array}$} & \multicolumn{2}{|c|}{ KUO } & \multirow{2}{*}{$\begin{array}{c}\text { Sira } \\
\text { No }\end{array}$} & \multicolumn{2}{|c|}{ KUO } \\
\hline & PAA & TCE & & PAA & TCE & & PAA & TCE \\
\hline 1 & 44,21 & 55,53 & 17 & 43,10 & 50,83 & 32 & 42,47 & 50,24 \\
\hline 2 & 30,90 & 59,63 & 18 & 41,82 & 53,40 & 33 & 41,90 & 54,98 \\
\hline 3 & 51,06 & 42,48 & 19 & 25,41 & 62,90 & 34 & 36,52 & 45,45 \\
\hline 4 & 53,07 & 54,67 & 20 & 53,86 & 54,07 & 35 & 37,90 & 53,27 \\
\hline 5 & 40,68 & 63,78 & 21 & 42,28 & 53,76 & 36 & 47,17 & 52,97 \\
\hline 6 & 29,62 & 64,71 & 22 & 33,21 & 64,17 & 37 & 44,41 & 53,13 \\
\hline 7 & 53,50 & 39,53 & 23 & 43,32 & 64,81 & 38 & 51,15 & 46,48 \\
\hline 8 & 37,54 & 56,95 & 24 & 44,21 & 55,53 & 39 & 54,35 & 43,10 \\
\hline 9 & 35,42 & 56,89 & 25 & 44,21 & 55,53 & 40 & 35,92 & 51,08 \\
\hline 10 & 52,40 & 50,74 & 26 & 43,75 & 62,72 & 41 & 32,53 & 62,40 \\
\hline 11 & 28,84 & 51,76 & 27 & 44,21 & 55,53 & 42 & 46,04 & 69,35 \\
\hline 12 & 34,87 & 63,20 & 28 & 43,55 & 48,58 & 43 & 42,91 & 50,22 \\
\hline 13 & 36,36 & 64,57 & 29 & 44,21 & 55,53 & 44 & 44,21 & 55,53 \\
\hline 14 & 33,96 & 66,23 & 30 & 38,66 & 66,58 & 45 & 56,01 & 64,60 \\
\hline 15 & 40,00 & 57,50 & 31 & 40,12 & 53,85 & 46 & 46,43 & 48,20 \\
\hline 16 & 34,15 & 71,08 & & & & & & \\
\hline
\end{tabular}

Çizelge 6. Klasik ısıtmada kükürt uzaklaştırma oranı için 2.derece regrasyon modelleri ve katsayıları.

\begin{tabular}{|c|c|c|}
\hline Kimyasal & Regrasyon Modeli & $\mathbf{R}^{2}$ \\
\hline PAA & $\begin{array}{c}32,67-1,25 \times K K-0,433 \times S+0,259 \times Z+0,033 \times K H+0,936 \times K O-0,0216 \times K K^{2}+5,565 \times 10^{-4} \times S^{2}- \\
1,242 \times 10^{-3} \times Z^{2}-2,464 \times 10^{-6} \times K^{2}-0,031 \times K O^{2}+0,0055 \times K K \times S+0,010 \times K K \times Z+8,88 \times 10^{-} \\
{ }^{5} \times K K \times K H+0,062 \times K K \times K O-7,407 \times 10^{-4} \times S \times Z-1,778 \times 10^{-4} \times S \times K H-1,0867 \times 10^{-2} \times S \times K O-2,073 \times 10^{-} \\
{ }^{4} \times Z \times K H-7,405 \times 10^{-4} \times Z \times K O-7,11 \times 10^{-4} \times K H \times K O\end{array}$ & 91,93 \\
\hline TCE & 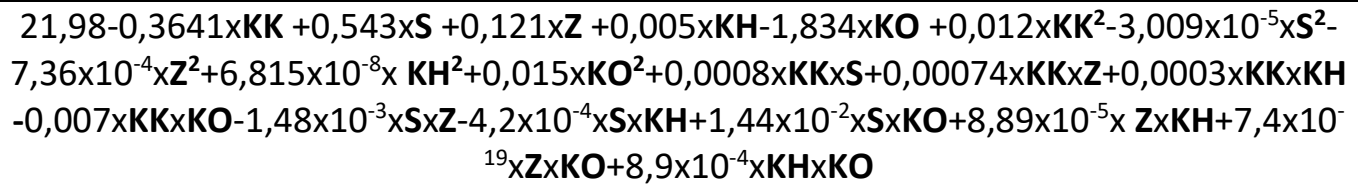 & 86,19 \\
\hline
\end{tabular}


Çizelge 7. Klasik ısıtma yöntemi organik kükürt analiz sonuçları

\begin{tabular}{l|cc|cccc}
\hline & \multicolumn{3}{c}{ Besleme (\%) } & \multicolumn{4}{c}{ Temiz Kömür (\%) } \\
Kimyasal & $\begin{array}{l}\text { Toplam } \\
\text { Kükürt }\end{array}$ & $\begin{array}{l}\text { Organik } \\
\text { Kükürt }\end{array}$ & $\begin{array}{l}\text { Toplam } \\
\text { Kükürt }\end{array}$ & KUO & $\begin{array}{l}\text { Organik } \\
\text { Kükürt }\end{array}$ & OKUO \\
\hline PAA & 4,77 & 3,67 & 2,09 & 56,01 & 1,21 & 67,90 \\
\hline TCE & 4,77 & 3,67 & 1,38 & 71,08 & 0,62 & 83,55 \\
\hline
\end{tabular}

Sonuçlar klasik isıtma yöntemiyle karışlaştırılırsa PAA ile elde edilen en iyi sonuçlarda mikrodalga enerjisi kullanıldığında \%7 daha fazla kükürt uzaklaştırılma oranı elde edilmiştir. TCE ile yapılan deneylerde en iyi sonuçlarda mikrodalga enerjisi kullanıldığında \%5 daha fazla kükürt uzaklaştırma oranı elde edilmiştir. Ayrıca mikrodalga enerjisi daha fazla kükürt uzaklaştırmanın dışında zamandan ve dolayısıyla tüketilen enerjiden büyük avantaj sağlamaktadır. Klasik isıtma yönteminde her iki kimyasal ile yapılan çalışmalarda optimum sonuçlar $75 \mathrm{dk}$ 'da elde edilirken mikrodalga 1sıtma yönteminde 12,5 dk' da elde edilmektedir. Yani 6 kat daha kısa sürede daha yüksek kükürt uzaklaştırma oranı elde edilmiştir.

Çizelge 8. Mikrodalga ısıtma yöntemi test sonuçları.

\begin{tabular}{|c|c|c|c|c|c|c|c|c|}
\hline \multirow{2}{*}{$\begin{array}{c}\text { Sira } \\
\text { No }\end{array}$} & \multicolumn{2}{|c|}{ SRR } & \multirow{2}{*}{$\begin{array}{c}\text { Sira } \\
\text { No }\end{array}$} & \multicolumn{2}{|c|}{ SRR } & \multirow{2}{*}{$\begin{array}{c}\text { Sira } \\
\text { No }\end{array}$} & \multicolumn{2}{|c|}{ SRR } \\
\hline & PAA & TCE & & PAA & TCE & & PAA & TCE \\
\hline 1 & 56,55 & 55,76 & 10 & 45,13 & 61,72 & 19 & 36,59 & 71,32 \\
\hline 2 & 41,50 & 49,85 & 11 & 33,96 & 56,26 & 20 & 47,57 & 57,77 \\
\hline 3 & 32,46 & 58,97 & 12 & 45,13 & 61,72 & 21 & 34,93 & 65,64 \\
\hline 4 & 40,45 & 71,71 & 13 & 62,97 & 61,87 & 22 & 30,35 & 75,94 \\
\hline 5 & 45,13 & 61,72 & 14 & 40,85 & 72,67 & 23 & 45,75 & 69,73 \\
\hline 6 & 50,26 & 71,20 & 15 & 56,83 & 57,37 & 24 & 48,18 & 71,23 \\
\hline 7 & 37,95 & 59,67 & 16 & 38,89 & 50,98 & 25 & 59,38 & 67,82 \\
\hline 8 & 59,94 & 52,01 & 17 & 43,96 & 54,49 & 26 & 46,06 & 63,15 \\
\hline 9 & 41,90 & 72,23 & 18 & 49,48 & 66,32 & 27 & 47,97 & 65,06 \\
\hline
\end{tabular}

Çizelge 9. Mikrodalga ısıtmada kükürt uzaklaştırma oranı için 2.derece regrasyon modelleri ve katsayıları

\begin{tabular}{|c|c|c|}
\hline Kimyasal & Regrasyon Modeli & $\mathbf{R}^{2}$ \\
\hline PAA & 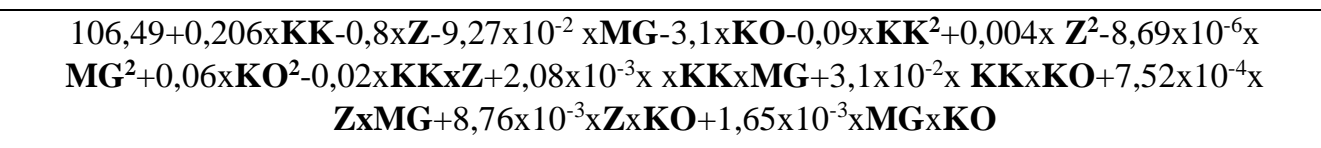 & 77,07 \\
\hline TCE & 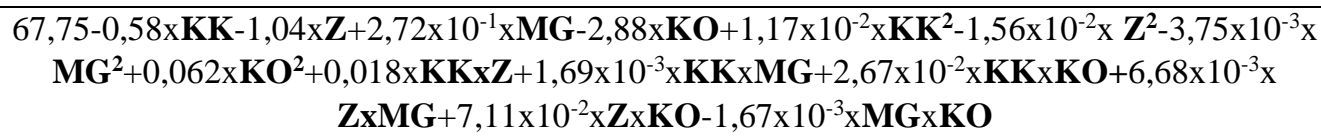 & 78,53 \\
\hline
\end{tabular}


Klasik 1sitma yönteminde olduğu gibi mikrodalga 1sıtma deneyleri sonrası en yüksek kükürt uzaklaştırma oranlarının elde edildiği deneylerdeki kömür örneklerinin organik kükürt uzaklaştırma oranlarını belirlemek için organik kükürt analizleri yapılmıştır. PAA için 13 nolu deneyden elde edilen kömür örneği ve TCE için 22 nolu deneyden elde edilen kömür örneğine ait organik kükürt analiz sonuçları Çizelge 10'da verilmiştir. Çizelgeden de görüldüğü gibi PAA kimyasalı kullanıldığında \%62,97 toplam kükürt uzaklaştırma oranı (KUO) elde edilirken \%69,75 organik kükürt uzaklaştırma oranı (OKUO) elde edilmiştir. TCE kimyasalında ise $\% 75,94 \mathrm{KUO}$ elde edilirken \%86,10 OKUO elde edilmiştir. Görüldüğü gibi toplam kükürt oranı en yüksek elde edilen TCE ile organik kükürdün neredeyse tamamına yakını uzaklaştırılmıştır.

Çizelge 10. Mikrodalga ısıtma yöntemi organik kükürt analiz sonuçları.

\begin{tabular}{l|cc|cccc}
\hline & \multicolumn{3}{c}{ Besleme (\%) } & \multicolumn{4}{c}{ Temiz Kömür (\%) } & \multirow{2}{*}{ Kimyasal } \\
& Toplam & Organik & Toplam & KUO & Organik & OKUO \\
& Kükürt & Kükürt & Kükürt & & Kükürt & \\
\hline PAA & 4,77 & 3,67 & 1,77 & 62,97 & 1,11 & 69,75 \\
\hline TCE & 4,77 & 3,67 & 1,15 & 75,94 & 0,51 & 86,10 \\
\hline
\end{tabular}

\section{Kükürt Uzaklaştırma Oranına Klasik Isıtma}

\section{Değişkenlerinin Etkisi}

Sonuçların daha iyi anlaşılması ve kükürt uzaklaştırma oranına klasik ısıtma deneylerinde değişken parametrelerin etkisini görmek için en iyi KUO elde edilen tetrachloroethylene deneylerindeki sonuçlar kullanılarak iki boyutlu grafikler çizilmiştir (Şekil 1). Şekillerde klasik 1sıtma deneylerindeki herbir değişkenin kükürt uzaklaştırma oranına etkisi karşılaştırılmıştır. Çizimler için diğer dört değişkenin orta seviyesi kullanılmıştır.

Şekil 1'den de görüldüğü gibi klasik 1sitma deneylerinde kullanılan bütün değişken parametrelerin kükürt uzaklaştırma oranına pozitif etkisi olmuştur. Ancak bu etki bazılarında sınırlı miktarda kalmıştır. Bir reaksiyonun en önemli parametrelerinden birisi kimyasal konsantrasyondur. Şekil 1A'da kimyasal konsantrasyonun etkisi görülmektedir. 0,1 M tetrachloroethylene kullanıldığında $\% 50$ civarında KUO elde edilirken 0,3 M'da \%70 civarına ulaşmıştır. Yani yaklaşık \%20 civarında bir artış elde edilmiştir. Kimyasal reaksiyon hızını değiştirebilecek bir diğer önemli parametre ise reaksiyon sıcaklığıdır. Şekil 1B'de ise reaksiyon sıcaklığının değişiminde KUO'nın nasıl değiştiği görülmektedir. $30{ }^{\circ} \mathrm{C}^{\prime} \mathrm{de} \% 50$ oranında KUO elde edilirken $90{ }^{\circ} \mathrm{C}$ 'de bu oran \%62'lere çıkmıştır. Diğer parametrelerden reaksiyon zamanı ise Şekil 1C'de görülmektedir. Burada ise ilk 30 dakikada KUO'nı \%50 civarında elde edilirken 120 dakikada ancak \%58'lere çıkalabilmiştir. Yani gerçekleşen KUO'nın büyük kısmı ilk 30 dakika içerisinde gerçekleşmektedir. Diğer parametrelerden karıștırma hızı ve katı oranı da sırasıyla Șekil 1D ve $1 \mathrm{E}$ 'de görülmektedir. Bu değişkenlerin diğer parametrelerde olduğu gibi dikkate değer bir etkisi olmamıştır.

\section{Kükürt Uzaklaştırma Oranına Mikrodalga Isıtma Değişkenlerinin Etkisi}

Klasik 1sıtma deneylerinde olduğu gibi en iyi KUO elde edilen tetrachloroethylene deneylerindeki sonuçlar kullanılarak kükürt uzaklaştırma oranına mikrodalga 1sıtma deneylerindeki değişken parametrelerin etkisini görmek için iki boyutlu grafikler çizilmiştir (Şekil 2). Şekillerde mikrodalga 1sitma deneylerindeki herbir değișkenin kükürt uzaklaştırma oranına etkisi karşılaştırılmıştır. Çizimler için diğer üç değişkenin orta seviyesi kullanılmıştır. 

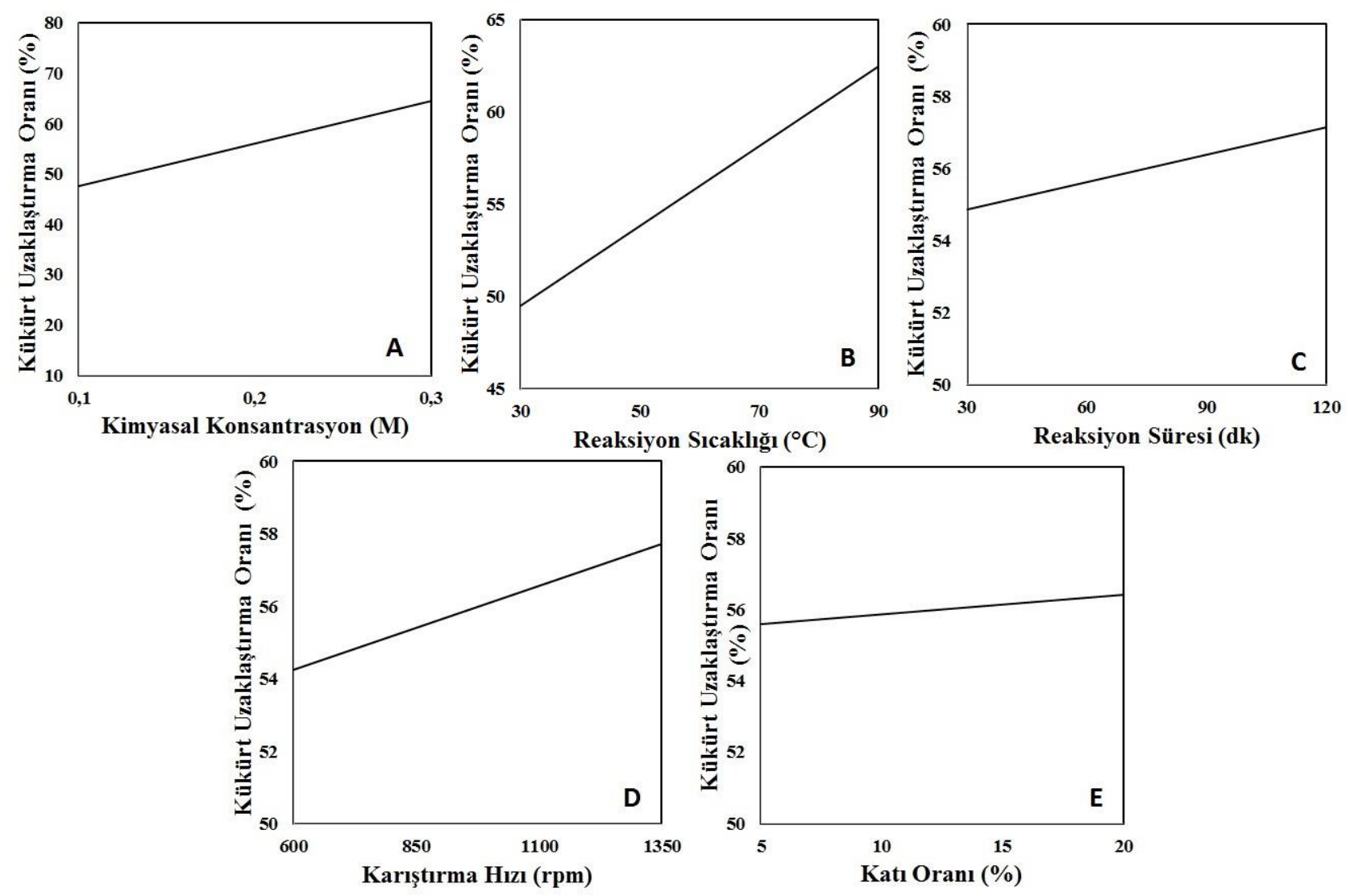

Şekil 1. Kükürt uzaklaştırma oranına klasik ısıtma değişkenlerinin etkisi.

Şekil 2'den de görüldüğü gibi bütün değişken parametrelerin kükürt uzaklaştırma oranına pozitif etkisi olmuştur. Bunlar içerisinde en dikkat çekeni klasik isıtma deneylerinde olduğu gibi kimyasal konsantrasyondur. Şekil 2A'daki kimyasal konsantrasyon etkisine bakıldığında KUO'nın \%55'den \%76'lara çıktığı görülmektedir. Diğer bir önemli parametre ise reaksiyon süresidir (Şekil 2B). Burada 5. Dakikada \%62 lerde olan KUO'nın 20. dakikada \%64'lere çıktığı görülmektedir.
KUO'nın önemli bir kısmının ilk 5 dakika içerisinde meyadana geldiği görülmektedir. Şekil 2C'deki mikrodalga gücünde de 400$1200 \mathrm{~W}$ arasındaki KUO değişimi görülmektedir. Burada da KUO \%62-65 arasında değişim göstermiş olup en iyyi sonuçlar 1200 W'ta elde edilmiştir. Diğer parametre ise Şekil 2D'de görülen katı oranıdır. Klasik 1sıtmada olduğu gibi bu parametrenin de KUO'nda \%1'lik bir değişim meydana getirmiştir. 

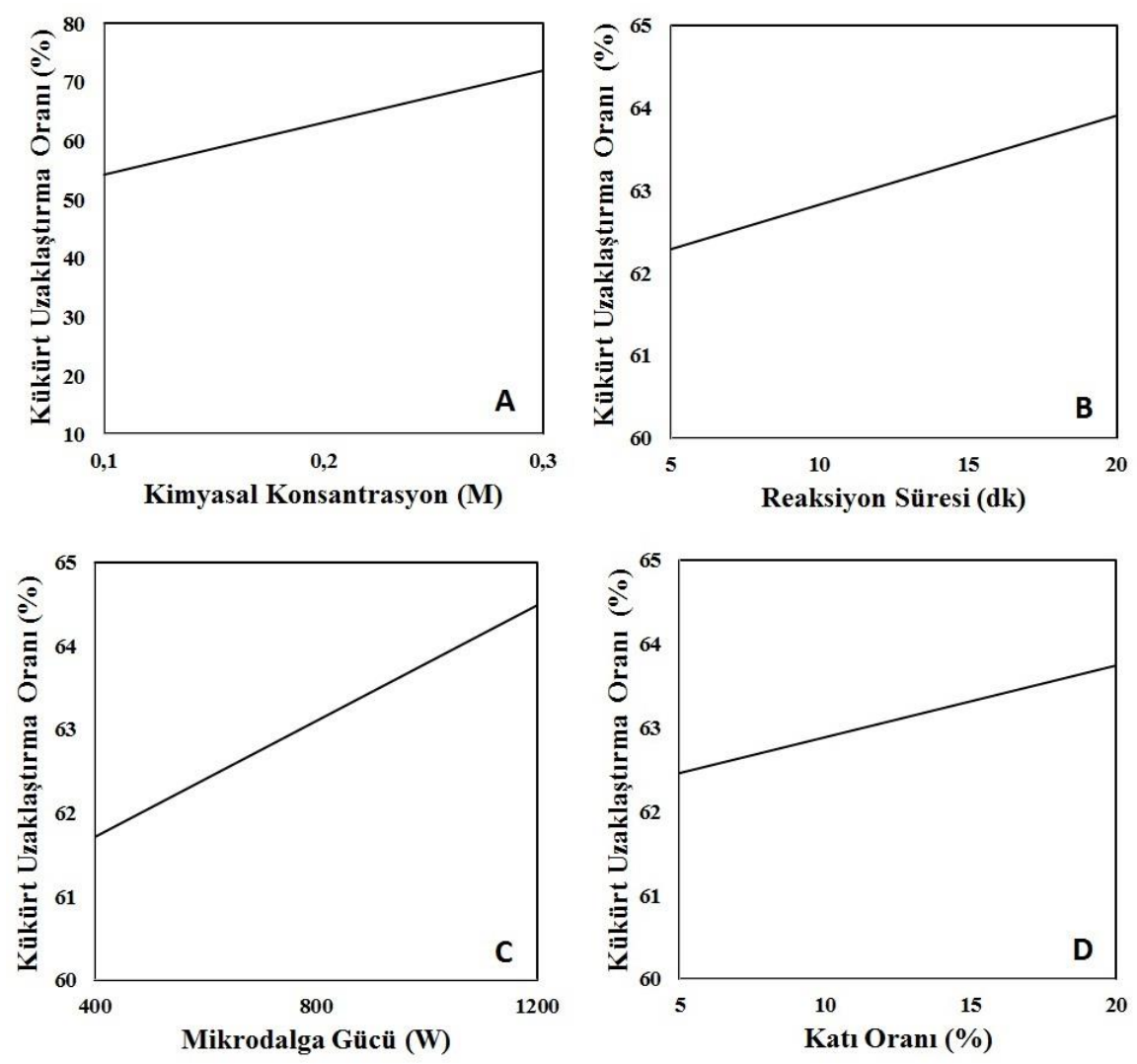

Şekil 2. Kükürt uzaklaştırma oranına mikrodalga ısıtma değişkenlerinin etkisi

\section{Sonuçlar}

$\mathrm{Bu}$ çalışmada, 2 farklı kimyasal (tetrachloroethylene ve peroksiasetik asit) kullanarak kömürdeki kükürdün, özellikle de organik kükürdün uzaklaştırılması araştırılmıştır. Ayrica klasik 1sitma ve mikrodalga 1sitma yöntemlerinin kükürt uzaklaştırmaya etkiside belirlenmiştir. Isıtma yöntemlerinde optimum şartlar belirlenerek çalışma parametrelerin etkisini görmek için 2D grafikler çizilmiştir. Çalışmalarda, ülkemizdeki önemli kömür rezervlerine sahip Çanakkale/Çan bölgesine ait $\% 4,77$ toplam kükürt $\% 3,67$ organik kükürt içeren kömürler kullanılmıştır. Yapılan deneyler sonucunda en yüksek kükürt uzaklaştırma oranı tetrachloroethylene (TCE) kimyasalı ile elde edilmiş olup klasik ısıtma yönteminde toplam kükürt \%1,38'e organik kükürt ise \%0,62'ye düşürülmüştür. Mikrodalga 1sıtma yönteminde ise toplam kükürt içeriği \%1,15'e düşürülürken organik kükürt içeriği \%0,51'e düşürülmüştür. Diğer bir değişle toplam kükürdün \%75,94'ü, organik kükürdün ise \%86,10’u uzaklaştırılmıştır. Daha önceki çalışmalarda PAA ile \%80 kükürt uzaklaştırma oranına ve TCE ile \%53,1 kükürt uzaklaştırma oranına ulaşılmasına ragmen bu çalışmada daha iyi sonuçlar elde edilerek organic kükürdün \%86,10'u uzaklaştırılmıştır. Bu farklılıkların en önemli nedeni kömür içerisindeki organik kükürdün türüdür. Bilindiği gibi organik kükürt kendi içinde alifatik, aromatik ve tiyofen kükürt olarak ayrılır. Bu durum kullanılan kimyasal ile tepkisini büyük ölçüde değiştirir. Aynı bölge kömürlerinde aynı kimyasallar kullanılarak farklı kükürt uzaklaştırma oranları elde etmek mümükündür.

Ayrıca, çalışmalar sonucunda mikrodalga 1sıtmanın çok daha fazla kükürt uzaklaştırma sağladığ 1 ve bunu klasik 1sıtma yöntemine göre yaklaşı 1/ $1 / 6$ reaksiyon süresinde gerçekleştirdiği belirlenmiştir. $\mathrm{Bu}$ durumun enerji sarfiyatında çok ciddi tasarruf sağlayacağı açıktır. Ancak, çok ciddi oranda kükürt uzaklaştırılmış olması ve 
bunu düşük enerji sarfiyatı kullanarak yapılmış olmasına rağmen bir kimyasal kullanılması çevresel bir takım sorunları beraberinde getirecektir. $\mathrm{Bu}$ yüzden sürecin devamlılığı ve sonuçların uygulanabilirliği için sonraki çalışmalarda geriye çıkan atık suyundan tetrachloroethylene kimyasalının ve kükürdün kazanılması araştırılmalıdır. Günümüz şartlarında kullanılması mümkün olmayan bu prosesin eksik yönleri tamamlandığında gelecekte kullanılabilecek bir yöntem olarak karşımıza çıkacaktır.

\section{Kaynaklar}

[1] Ekinci, E., Tırıs, M. ve Okutan, H., (1994). Termik Santraller ve Emisyon Kontrolü, Gökova Körfezi Çevre Sorunları ve Çevre Yöntemi Sempozyumu, 2830 Haziran, İzmir.

[2] Çift, B.D., ve Okutan, H., (2010). Baca Gazı Desülfürizasyon Proseslerinin Ekonomik ve Teknik Analizi, ITÜ Dergisi, 9(4), 85-96.

[3] Chakrabarti, J., (1978). Analytical procedures for sulfur in coal desulfurization products C.J. Karr (Eds) Analytical Methods for Coal and Coal Products, Academic Press, New York 279-323.

[4] Leonard, J.W., (1979). Coal Preparation, The American Institute of Mining and Metallurgy and Petroleum Engineers.

[5] Wills, B.A., (1988). Mineral Processing Technology, Pregamon Press, Oxford, 456p.

[6] Göktepe, F., (2002). Kömür Flotasyonunda Bakteri İlavesinin Piritik Kükürt Uzaklaştırmasına Etkisi, Türkiye 13. Kömür Kongresi, Zonguldak, 125-132.

[7] Karaca, S., Akyürek, M., and Bayrakçeken, S., (2003). The Removal of Pyritic Sulfur from Askale Lignite in Aqueous Suspention by Nitric Acid, Fuel Processing Technology, 80, 1-8.

[8] Levent, M., Kaya, Ö., Kocakerim, M., Yiğit, V., and Küçük, Ö., (2007). Optimization of Desulphurization of Artvin-Yusufeli Lignite with Acidic Hydrogen Peroxide Solutions, Fuel, 86, 983-992.

[9] Alam, H.G., Moghaddam, A.Z, and Omidkhah, M.R., (2008). The İnfluence of Process Parameters on Desulfuruzation of Mezino Caol by $\mathrm{HNO}_{3} / \mathrm{HCl}$ Leaching, Fuel Processing Technology, 90, 1-7.
[10] Demir, U., (2011). Kütahya-Gediz Yöresi Kömürlerindeki Kükürdün Uzaklaştırılması, Dumlupınar Üniversitesi Fen Bilimleri EnstitüsüDoktora Tezi, 277s.

[11] Palmer, S.R., Hippo, E.J., and Liu, Y., (1995). Oxidative Pretreatments for the Enhanced Removal of Organic Sulfur from Coal, Coal Science, 17131716.

[12] Zhao, J.L., Zhang, Y.Y., Chen, Q., and Fu, Q., (2002). Study on Removal of Organic Sulfur from Coal by Glacial Acetic Acid-Hydrogen Peroxide Oxidation Process, Environ Prot Chem Ind., 22(5), 249-253.

[13] Jorjani, E., Rezai, B., Vossouhgi, M., and Osanloo, M., (2004). Desulfurization of Tabas Coal with Microwave Irridation/Peroxyacetic Acid Washing at 25, 55 and $85{ }^{\circ} \mathrm{C}$, Fuel, 83, 943-949.

[14] Jorjani, E,. Rezai, B., Vossoughi, M., Osanloo, M., and Abdollahi, M., (2004). Oxidation pretreatment for Enhancing Desulfurization of Coal with Sodium Butoxide, Minerals Engineering, 17, 545-552.

[15] Sönmez, Ö., and Giray, E.S., (2001). The Influence of Process Parameters on Desulphurization of Two Turkish Lignite by Selective Oxidation, Fuel Processing Technology, 70, 159-169.

[16] Ahmed, M., and Rahim, A., (1995). Chemical Desulphurization Methods of Organic Sulphur of Eocene Coal, Coal Science, 1721-1724.

[17] Zhao, J.L., Zhang, Y.Y., Wang, H.W., and Chen, Q.Y., (2002). Desulfurization of High Organic Sulfur Coal by Tetrachloroethylene Extraction under Ultrasonic Field, Journal of Fuel Chemistry and Technology, 30(3), 234-237.

[18] Longjun X., Dejun Z., and Yujuan C., (2006). Study on Removal of Organic Sulfur From Coal by 1-Phrpyl Alcohol, Coal Convers, 29(4), 13-6.

[19] Mi, J., Ren, J., Wang, J.C., Bao, W.R., and Xie, K.C., (2007). Ultrasonic and Microwave Desulfurization of Coal in Tetrachloroethylene, Energy Sources Part A, 29, 1261-1268.

[20] Mi, J., and Wei, R., (2011). Microwave Applied in Coal Desulfurization Process, Applied Mechanics and Materials, 71-78, 2122-2126.

[21] Jie, M., Jiancheng, W., Jun, R., Weiren, B., Yongqing, Y., Kechang, X., (2008). Study on Forms of Sulfur in NW Coal and Behavior of Desulfurization. 2nd International Bioinformtics and Biomedical Engineering confesans, 4633-4636. 